\title{
COVID-19: Harbinger of a New Psychology of Religion for Postcolonial Societies
}

\author{
James J. Akpan ${ }^{1}$ \\ Received: 15 July 2020 / Revised: 27 October 2020 / Accepted: 16 November 2020 / \\ Published online: 24 November 2020 \\ (c) Springer Nature Switzerland AG 2020
}

\begin{abstract}
Religious practice, like every other human affair, was alteredat the onset of the pandemic. The paper argues that the "home church" as a Christian expression of religiosity during Covid-19, for instance, was a signalto something new at least in the theoretical realms of religion. More strongly,it was a vindication of postcolonial native societies (of Africa) whoseindigenous spiritualities were thwarted and/or abolished during the colonialera. The pandemic is theorized as a wake-up call for agency in these societies. The theorization relies upon Piaget's psychological "techniques" ofaccommodation and assimilation, opening various channels to answering thequestions: what was assimilated during colonialism that should have beenaccommodated and vice versa? And how has the pandemic uncovered that error ofinversion?
\end{abstract}

Keywords Covid-19 $\cdot$ Religion · Psychology $\cdot$ Accommodation · Assimilation · Equilibration · Postcolonial Africa

\section{Introduction}

One finds no better words to describe the state of human brokenness due to Covid-19 than those of Brene Brown: "In these uncertain and risky moments of vulnerability, I search for inspiration from the brave innovators and disrupters whose courage feels contagious" (Brown 2017). These words can help as we navigate through what we may call crisis discourse at the intersection between (postcolonial) society and (foreign) religion using the tools of psychology. Jean Piaget would be among Brown's categories of "brave innovators"; his psychological theories have lots of meaningful ideas to offer especially to postcolonial societies in their post Covid-19 practice of religion. Even though the idea of God has brought dissension and rupture to social relations especially in contemporary society, religious practices have become a defining attribute for many people (Chappell Tomcho, and Foels 2020), more so during crisis. Yet, as "animals of habit," our routines can empty itself of the primary treasures we found in the activities we intentionally engaged in, including

James J. Akpan

jakpan1@my.westga.edu

1 Psychology: Consciousness and Society, University of West Georgia, 316 Columbia Dr. \#324B, Carrollton, GA 30117, USA 
religion. "Automaticity is the peril of repetition" (Kunkel 2018). Thus, the Covid-19 pandemic has rolled back some critical platforms for societies to reason together, and we can only hope that these avenues are utilized for good.

The overall aim of this paper is to evaluate what is changing (or ought to change) in the practice of religion in the world and especially in postcolonial societies because of the pandemic. It is a sympathetic stance with indigenous peoples whose primary spiritualities were altered by colonialism. Thus, we shall begin with the fundamentals of the pandemic in a global scene, particularly, the differences perceived and lived in two countries-Nigeria and the USA - as we saw through the social media and societal levels of interaction. From that brief comparison, we shall narrow our focus to the way religion functions in postcolonial African societies, including Nigeria. Then, we shall examine what psychological cues the pandemic is bringing. The paper shall then treat Piaget's learning and developmental theories of assimilation and accommodation, raising the question of their implications at the intersection between society and religion, especially in Africa. In doing that, we also keep in mind that Africa's major religious characters are still very colonial, that is, alienated from the people and the land. The paper argues that social happenings in the inter-religious terrain, especially the killings of Christians in Nigeria, is a symptom of the dangerous inversion of the theories of accommodation and assimilation having its roots in the colonial era. This argument further shows the need for psychological attention to religions in these societies; Covid-19 has made it even more urgent.

At the onset of the pandemic, everyone went back to his/her families, and personal responsibility towards oneself and one's primary group could not be better negotiated. This form of responsibility spilled over to the societal level of life. These ideas should not just stop at the disease control instinctual level of life; it should be allowed to flow into the realms of psychosocial agency to chart a better course for postcolonial societies. To begin our discourse, we shall take a brief look at the initial experience of the pandemic and how that delineates the differences in societies, paving the way for a deeper discourse on postcolonial expression of religiosity, especially in Africa.

\section{Establishing the Foundation: Different Local Experiences, One Global Crisis}

Covid-19, like every other world crisis, was experienced differently (locally) at different parts of the world, some worse than others. This knowledge opens a critical landscape to re-evaluate what "global" means for each society. We had a worse situation in the USA with New York being the prior epicenter of the virus. Yet, students were still doing their "work" in the USA, while everyone of their counterpart in Nigeria was home "doing" nothing. Social distancing was easy to observe in America, and the pandemic became, for some, an opportunity to see what they could achieve through technology. It was like the reality TV program, Survivor, where, as the name implies, participants are tested on their instinct to survive through difficult tasks. Religious functions were streamed online, and one imagines a deeper exploration of the social media for friendship and educational purposes during the crisis. The bottom-line was learning more about what people could do with the tools in their hands (Kunkel 2018). But that was not the case in areas that do not even have a stable electricity; neither would they gain from the home experience except to help in family farms as rural Nigerian students did. 
As the stimulus checks were reaching Americans in their homes, the "common people" in Nigerian communities could not even receive the raw food items distributed; it all ended in the households of a few-the leaders and their intermediaries. We also saw from American TV outlets what pandemonium took place in the scenes of food distribution in Africa. While some American students were beginning to take their colleges and universities to court for tuition refunds, a typical Nigerian student would be contented to be called back to complete the academic year. As some Americans were protesting the lockdown and quarantine, organizing themselves as a voice that will bring them out of seclusion (an action that was open to different opinions), the Nigerian citizens of the same status were just whispering behind closed doors because their voices are not recognized as significant by their so-called leaders. Even during the lockdown, food shopping and other essential activities were still done by Americans, with security agencies, first responders, and health care workers aiding the process. In Nigeria, there were alleged corrupt practices on the road, with police officers and "local boys" extorting people who were carrying out their essential services to keep their lives going. There was even a video circulating on the social media about an alleged killing of a motorist by a member of the Nigerian Police for not wearing his face mask! A voice (purportedly of the person taking the video) was heard lamenting such inhuman act and saying: "The Nigerian Police have killed (Nigerians) much more than Covid-19."

Again, the pandemic can be a time to rethink some of the implications of the terms we use in the global society. Like virtually everything else between the two countries, something is missing in one, that is present in the other. The missing piece is what Roth (2018) would term "the 'C' factor." The meaning is not far-fetched: one country organizes itself as a 'social' entity (with no reliable rules) while the other shows itself to be 'societal.' The 'A' factor is the individual; the ' $\mathrm{B}$ ' is two (and more) individuals making the social; and the ' $\mathrm{C}$ ' is the societal, which extracts, abstracts, and builds upon the solid foundation laid by both 'A' and 'B.' The ' $\mathrm{C}$ ' factor is behind standardizations such as the rule of law, functional education, respectable public life, and effective constitutional democracy. It is like the sun whose rays reach all (citizens) including the so-called insignificant members of the society. If the ' $\mathrm{C}$ ' factor is missing, then one can treat the 'social' as if it were the 'societal.' For instance, there are many local and international voices all talking about the nation of Nigeria as corrupt even when there is the constitution and written codes of conduct for public office holders. The inability to initiate a better national identity could possibly attest to the " 'C' factor deficit." The grave implication of that deficit is that so-called leaders (in Africa) do run the public office as if they were running their individual business with no respect for fellow citizens. In late October 2020, there was an unprecedented nation-wide protest by Nigerian youths against the inhuman pattern of governance as a testimony to some of the ideas shared here about Nigeria. Though government forces killed some of the protesters, we hope for a better leadership system for Africa.

The disparity between Nigeria and the USA as shown by Covid-19 reminds us of the theoretical and ideological origins of globalization or the events that are termed 'global.' For Tan (2006), "The word (globalization) was used to teach students in business administration with respect to how to market and often to establish production beyond the boundaries of their own nation-state" (p. 167). This meaning is built upon the foundation provided by Anthony Giddens who sees global events as a dialectical process of shaping local events by a similar event happening miles away in "distant localities" and vice versa. For him, "Local transformation is as much a part of globalization as the lateral extension of social connection across time and space" (Tan 2006). In the narrow sense of global event, we saw the respective roles of each nation and states within the nation as they searched for the best 
ways of appropriating science, politics, and common sense during the crisis, particularly in the USA.

Also, Covid-19 as experienced locally, reminds us of the diathesis-stress model of crisis/management. This model sees "predispositional vulnerabilities" as fundamental to life in general and to crisis. Stress is always already a part of our (human/daily) life, and all that matters is to regulate and keep the stress level always to the positive, the "eustress" (Kunkel 2017). But our predispositional vulnerability would always show up should we reach a breaking point during extreme stress. Applied to the societal level, Covid-19 revealed what lies "hidden" (the predispositional vulnerabilities) in different places, offering us cues to tackling the issues. Again, looking at the Nigerian societal living of the pandemic, a clue as to what is still lacking emerges! Agency! And we shall take this up in relation to religion as a framework in that society and other African societies. The above brief comparison between Nigeria and the USA was meant to open up the world of postcolonial societies for discussion especially in relation to the pandemic and with the idea of "home religion" (or more specifically, "home church") that was in vogue at the onset of the pandemic.

\section{The Practice of Religion in Postcolonial Societies Until Now?}

"Since its independence in 1960," writes Sampson (2014), "Nigeria has struggled unsuccessfully to clearly articulate the relationship between religion and the state." The paradox left behind by the British colonial government amounts to what Sampson calls "the Achilles' heel of Nigeria's corporate existence." The Muslim north and the Christian south have come to define postmodern Nigeria with all its thick internal demarcations that would disqualify an entity as a nation. There is a "strong animosity" among adherents of the two major religions in Nigeria: Islam and Christianity. But prior to the coming of the colonial master, the ethnic entities that have made up the present-day country called Nigeria were all small kingdoms with their own governing systems until the amalgamation of what came to be known as the northern and southern protectorates in 1914 by Lord Lugard. Even at that, the religious identities were still very thick - the Muslim north and the Christian south. According to Sampson, "the transition from an Anglo-Fulani colonial northern government to a modern democratic Nigeria based on egalitarianism came to the northern oligarchy as a rude shock" (p. 321). This was largely due to the ideology of governance as power (not service?) which had defined the northern region of Nigeria with its Islamic leanings, and in existence before the arrival of the British colonial system.

Religion, in some sense, functions like the Winnicottian maternal holding environment (Kellond 2019) to many. In Christianity, the church becomes the holding environment. And indeed, Pope John XXIII (papacy years: 1958-1963) describes the church-which offers an outlet for Christian religious experience-as "mother and teacher" (mater et magistra). But how do these ideas apply to places whose religiosity is determined from the outside? [Elsewhere, I have raised a similar question in the realms of psychoanalysis: who is the true mother of Africa - the primitive or the civilized? (Akpan 2020).] These questions are important since the African expression of religiosity is largely determined by the socalled mainstream religions which originated from the outside as in geopolitical location. While the location of origin is not bad in itself, the colonial approach to these forms of religious identities brought a maladaptive way of functioning: as "enemies of the land and of the people," undermining the agency of the people who already had pre-existent religious identities. 
A literary expression of the enmity here inferred can be seen in the classic novel, Things Fall Apart Achebe (2017). shows how the missionaries came in, and without affirming or acknowledging the goodness in the already-so-religious lands, imposed their religions on the people. In fact, the title of that novel, which shows the divisive tone that has come to define postcolonial Africa, can also spread out to the domains of mainstream religions in the continent. In other words, if things fell apart among the patriarchs of the pre-colonial kingdoms because of the arrival of the Whiteman, then each facet of life - religion included — brought by the Whiteman, can share the blame of tearing the people apart. "The church had come and led many astray. Not only the low-born and the outcast but sometimes a worthy man had joined it" (Achebe 2017). Describing one prominent member of the society in which the novel is based, Achebe highlights that the man, Ogbuefi Ugonna, who felt proud to imbibe the new religion "had thought of the Feast (implying a Holy Communion in the Whiteman's church) in terms of eating and drinking, only more holy than the village variety" (p. 173). Later, the text adds: "... he (the White missionary) says that our customs are bad; and our own brothers who have taken up his religion also say that our customs are bad" (p. 175). Thus, privileging the foreigner's lifestyle over one's native land's is only a sign of what forms of alienation came with colonialism, establishing a background to understanding the struggles in these societies today.

Thus, postcolonial ideas, according to Stephen Frosh (Hook 2012, Foreword), are "concerned primarily with the techniques ('hidden chains') of colonialism as they still function both politically and psychologically in the 'post' era (Hook 2012). 'Post era' and the 'carryover effect' already betray a persistent (somehow maladaptive) relationship between two entities - the (former) colonizer and the colonized (Akpan in press). With that being said, some contemporary authors interested in the subject of religion and psychology do call our attention to the difference between religion and spirituality. This call is largely due to the attribution of religion to colonialism and spirituality to the indigenous peoples (Dueck and Marossy 2019). In context also, we can apply Alfred Schutz's theory of relevance to the subject, deciphering religion (brought by a foreigner to people whose social lives were different) as an imposed relevance (Langsdorf 1980) to which the people should disentangle themselves.

\section{The Case of the Murdered Seminarian in Nigeria}

Right at the threshold of the pandemic, the news broke of the killing of a teenager, Michael Nnadi, a Nigerian seminarian, by kidnappers. The seminarian, who was just beginning his philosophical training and aiming for the Catholic priesthood in the northern diocese of Sokoto, was kidnapped alongside a few others. The others were released while Michael was murdered. The killing was said to be religiously motivated (Esteves 2020), re-echoing the need for a deeper assessment and action about the practice of religion in Africa and with the tools of psychology, remembering that the Rwanda genocide also happened among very religious people as well (Grzyb 2019). With that in mind, we want to turn over to Piaget's theories.

\section{Piaget on Accommodation and Assimilation}

Jean Piaget is known as the fourth most influential psychologist after B. F. Skinner, Sigmund Freud, and Albert Bandura (Beins 2016). Seen as having a meta-theoretical goal, Piaget is said to be striving towards harmony (Valsiner 2005). Prominent authors like Beilin have acknowledged that the works done on Piaget are "unrivaled" (Beins 2016). Even at that, he is also seen as not very easy to understand (Block 1982), and some of his 
theories regarding child development have been proven to be inconsistent though his timing has been said to be "propitious" (Beins 2016). Yet, among many other attributes, Piaget deserves accolades for his trio concepts of assimilation, accommodation, and equilibration. Treating the subjects under both cognitive ("I"/ "Me") and cultural ("We"/ "Us") realms, Rutherford (2011) associates Piaget's idea of assimilation with 'growth' and accommodation with 'change.' Despite the perception of esoterism in the distinction between the two primary Piagetian concepts (Block 1982), there is no doubt that growth and change are complementary. Clearly, assimilation and accommodation are not opposed to one another (Rutherford 2011) but offer what we need in our lived experience. "By becoming complementary to each other, both of them (assimilation and accommodation) change. Assimilating schemas become increasingly flexible in responding to the demands of the experience. Imitation loses its servility and becomes "intelligent" adaptation to the external world" (Valsiner 2005).

That notwithstanding, DeRobertis (2020) sees in the thoughts of Piaget a tilting towards the assimilatory angle, committing what DeRobertis calls "an assimilatory bias." This idea projects Piaget's overall contribution to psychology, and that was seeking "to carve out a substantive role for the subject to compensate for its diminished role in empirical psychology" (p. 5). Such would also be his contribution to the wider world of science which only legitimizes the third-person somewhat impersonal report. A question arises: is the Piagetian idea of the diminished role of the subject through assimilation parallel to the transpersonal notion of "allowing things to come to you" in human experience? This inquiry is important since both ideas seem to imply the diminishing of the individual subject's role in creating whatever experience is the focus. If that is the case, then, attribution becomes a central issue. It only follows logically that if I assimilate an experience in order to give a third-person report, according to Piagetian logic, then I should also give a first-person account since assimilation integrates the experience with an existing schema within the subject, making the subject one with his/her experience as it were. This is no different from mystical experience where the religious experiencer is said to be one with the divine (Lancaster 2004).

Piaget's assimilation bias, thus, counteracts what it sought to legitimize, that mainstream scientific method which only gives voice to a third-person narrative, can also explore parapsychological and transpersonal psychological methods as well, and consider "all persons" (first-, second-, or third-) as valid experiencers and sharers of knowledge (Blackmore and Troscianko 2018; Lancaster 2004). This is yet a theoretical wish as "Piaget remains committed to a conceptual schism that sets subjects with their schemes over against objects and their contents" (DeRobertis 2020). Be that as it may, we assume that a crisis happens as a part of both processes of growth and change. Again, life consists of both, and Piaget shows his diverse interest in life and development. He is known as "a participatory individual" whose logic of science goes beyond the Boolean logic (Valsiner 2005). "The logic of participation," which Piaget is attributed with, "becomes a phenomenon of feeling" (p. 59). That phenomenon starts very early in our developmental process. In his own words,

There are, to begin with, during a very early stage, feelings of participation accompanied sometimes by magical beliefs; the sun and moon follow us, and if we walk, it is enough to make them move along; things around notice us and obey us, like the wind, the cloud, the night, etc.; the moon, the street lamps, etc., send us dreams "to annoy us", etc. In short, the world is filled with tendencies and intentions which are in participation with our own" (Valsiner 2005, p. 60).

Affirming again in his very words, Piaget states that "No behavior, even if it is new to the individual, constitutes an absolute beginning. It is always grafted onto previous schemes and 
therefore amounts to assimilating new elements to already constructed structures" (Block 1982). As a meta-theorist interested in harmony, Piaget's foundational footprint in developmental psychology proves, through his theories of accommodation and assimilation, that there is no need for tipping the balance. It is not an "either/or" issue, but both are implicated in our developments. In the elements that define a thing, there is always something of accommodation and assimilation. Thus, these are not mutually exclusive terms; they co-exist but could, if weighed, show a different tendency for each person. The concepts of accommodation and assimilation are not just to be subjected to the realm of child development, as they have a lot to contribute to personality development in general. Conceiving them, by Piaget, as the "cardinal processes" for intelligent behavior of the child in the world, the two concepts extend through the process of equilibration into the realms of personality development and motivation (Block 1982) which might apply to the adult life as well.

Equilibration is seen not as a balance of opposing forces, but simply self-regulation brought about by the organism exploring the values of both accommodation and assimilation. In sum, there is a co-occurrence of assimilation and accommodation (Block 1982) through the equilibria processes. For Piaget, "Self-regulation by equilibration is central to learning, which is itself facilitated by supportive social conditions. However, self-regulation by equilibration is also an expression of the biological foundations of human development in that it fulfills human nature, which is inherently motivated to understand" (DeRobertis 2020).

Being "motivated to understand" says a lot about how humans crave for informed decisions during crisis. Also, since self-regulation is central to learning, as Piaget avers, a moment of crisis becomes a time when a society can explore all possible angles to learn more about itself. This exploration would mean listening to opposing voices sometimes, giving chances to all the voices, and invoking "the equilibration code," which is safety and life for all. But what if we accommodate what should be assimilated and vice versa? This question will be assessed with some of the social happenings within postcolonial societies in mind, like killing for religious purposes, and the opportunities for agency through the pandemic experience. So, in applying the two concepts within a societal spectrum, "growth" (assimilation) would apply to any idea brought by colonialism that had already existed in the land, like religion while "change" (accommodation) would typically accompany the difference brought during the said era, like formal education especially the tertiary model. Surprisingly, there is a space for both through equilibration (self-regulation). The point is that self-regulation could be a tilting idea for the African societies since the White-versus-Black (superior-versus-inferior) bias was always a part of the drive towards colonialism in the first place, implying that certain foreign ideas may have been assimilated that should have been accommodated. If that was the case (and most likely so), then, self-regulation, as in societal regulation, could function more like a patient struggling to stay alive and well, totally different from a healthy human person living in a selfregulatory manner.

\section{The Woes of Inversion and the Role of Agency}

It is common sense knowledge that using the right tool for the wrong reason can produce worse results. The same can be said of inversion, and in context, exchanging accommodation for assimilation. As learning theories, such an exchange was possible during the 
colonial era. For instance, the case of our subject matter-religion. Both Achebe (2017) and Sampson (2014) have acknowledged the pre-existence of indigenous religions, commonly tagged "African Traditional Religions" before the arrival of foreign religions. When the latter came to Africa, it logically meant "more religions" have arrived, further implying assimilation, that is, growth. The process of assimilation warrants that the learner puts new knowledge into the already existing schemata (Kunkel 2017). In Africa, that would imply bringing Christianity and Islam to bear on the religions of the land and making them "ours" by applying "our" already existing modes of worship and especially the prevalent polytheistic model at the time. That would have implied mutual acknowledgment (on the part of Nigerian Christians and Muslims) of the geopolitics that accompany the movement of such forms of life from one place to another. Future clashes and sometimes deadly encounters among these groups would have been forestalled. But that was not the case. In fact, accommodation (change) became the tool till now. Among entire ethnic groups, traditional religions vanished overnight, and persevering worshippers were cajoled as living in the past. Africans started [re]defining themselves using foreign parameters. Again, utilizing Schutz's idea, imposed relevance became the norm. Such was the literary tension in Things Fall Apart which led to the suicide of the protagonist, Okonkwo, for the insanity of his kinsmen who accommodated what should have been assimilated during colonialism. This main character died because of the error of inversion, which provides a lens to understanding what sort of learning deficits that postcolonial societies have incurred.

The psychological meaning and impact of inversion are not far-fetched: alienation. Simone Mayer, once an extern to Nigeria, captures the weight of alienation in the African continent using the lens of academic psychology. Comparing psychology in Nigeria with its Euro-American counterpart, she acknowledges that the former is influenced by the outside factor and the latter, 'hooked up in its own world of expertise' (Mayer 2002). The author gives some historical and socio-cultural differences that play important roles in the Nigerian milieu, like the issue of black inferiority and white superiority mentality. Mayer thinks much of Nigeria's problem is psychological in nature but wonders how that could be tackled being that Nigeria is still heavily influenced and dependent upon Euro-American ideologies and expertise like breakneck technological speed and neoliberal parameters. She also acknowledges the co-existence of pre-industrial and post-industrial mindsets among the population which can complicate the call for societal change. Mayer (2002) calls for indigenous psychology system which can handle the complex nature of Nigeria's sociocultural issues. This solution goes with her call on African psychologists to speak for themselves. Promoting indigenous psychology will help in understanding how Africans construct reality. What Mayer has done in comparative intercontinental psychology can apply to virtually every other aspect of Africa's postmodern societal life. In a way, her call is re-echoed by the pandemic which sent everyone back to his/her home and enacted agency at an optimal level.

Agency is the ability to take the lead in one's own affairs, the psychosocial knowledge that there is no undue interference from the outside. To be the self's/societal agent is to own one's experience. Though the neoliberal concept of the agentic self as a "flexible bundle of skills" has been critiqued (Gershon 2011), it is a fact that certain inter-racial skills were lacking on the part of the Africans during their first encounters with foreigners. Agency goes with a model of selfhood that is healthy or seeks to stay healthy and alive. Such a model includes aspects of life commonly known as "executive functions" (using the brain-biological terms): knowing and deciding, or knowing when to decide as well as utilizing the space of indeterminacy and discontinuity that always exists in decisive moments (Weiner 2011). There is no denial that these salient areas of 
life were blurred during colonial encounters as both parties-foreign and native-were not on the same page regarding self-definition and self-presentation.

Agency in postcolonial societies then implies initiating a form of movement, from the psychologic of givens (that is, relying solely on what comes from the outside) to that of affordances, that is, "the emotional possibilities for action and experience that exist in the relationship between participants (natives) and their environment..." (Bennett et al. 2019, emphasis added). The Black population has generally survived on the givens of civilization, of religion and of every other thing brought to their land by the colonialist, including sacred texts. In trying to re-create and replay the same cultural atmosphere that were the foundation of these imposed relevances, many things have gone wrong, and the entire societal life has become traumatic. The work of healing institutional/societal trauma implies moving from the given to the affordance, from non-agency to agency (Bennett et al. 2019). This could involve wrestling to retrieve control of one's own affairs. That is a part of the reminders wrought by the pandemic for postcolonial societies.

As practically experiential as Covid-19 has been, so should ideas about "the new mind about religion" ought to be. By this, it is implied that Piaget's theories of accommodation, assimilation, and equilibration would serve as psychological techniques in real-world scene for postcolonial societies. A beginning would be a question: what could happen if one assimilates what should be accommodated? Taking the question nearer to the context of postcolonial African societies, we could further tweak it: what was assimilated that should have been accommodated? Is there anything like false assimilation wherein the agent thought they had grown in a certain direction, but in reality, they are not? What was changed that should have been groomed?

\section{The Pandemic as Harbinger of a New Psychology of Religion}

Psychology of religion is predicated on the assumption that the worshipping human is also the thinking (feeling) being, hence, the need to study religious behavior as a part of human functioning (Chappell et al. 2020). One key religious idea to consider in this regard is the notion of the all-powerful healing God confined to a group's monopoly to the exclusion of the rest of us. That idea was challenged by the locked doors in houses of worship and the advice to stay out of those places. That was symbolic! Something of a more spiritual nature, overlooked for millennia, is looming large, particularly in the Christian world. Prior to the reopening, Christians, like their religious counterparts worldwide, had "the freedom" to worship God in their homes. The "home church" was challengingly symbolic too. It represented the idea that the Christian religion, which grew out of Judaism and claimed to have a more universal (spiritual) character, is yet to assume that character. Something of a spiritual nature is something that transcends time and space.

A critical question is what is the rational for choosing a single day (a particular space and time) of the week - Sunday - for a valid Christian worship of a reality that lies beyond space and time? Why not make everyday a valid day for worship? For Catholic Christians, Sunday is not just the day of worship but also the weekly holy day of obligation. Catholics who absent themselves from the Sunday gathering except for grave reasons like sickness, would have to confess and be absolved from that $\sin$ by a priest before they can participate fully in subsequent gatherings. The challenge is not the confession but the hegemonic and counter-intuitive choice of a single day of the week as a day of obligation for religious activities directed towards the spiritual realm. If the spiritual realm is larger than the physical, as popular acclaim 
holds, then it would be a mark of spiritual freedom to allow worshippers to come to church any day of the week and gain the same "amount" of graces that was hitherto reserved for Sunday. This insight is an example of what Covid-19 might be revealing, thus making psychology of religion a dynamic search for emerging tools (at a moment of crisis) to enhance our health and existential well-being.

Going back to our homes to worship the same God who was hitherto worshipped communally was a vindication of native lands whose model of (independent) spirituality was condemned during colonialism. The contemporary move towards reviving indigenous spirituality brings back the idea that, for psychologists of religion like William James, the worshipper was not just the religious one but the one who underwent a religious experience. Having an experience of the divine would be deeper than mere belonging to a group. "Abstract intellectual systemization" is a key characteristic of the latter while relating to a transcendent being is a hallmark of the former (Dueck and Marossy 2019). Experiencing the divine as a being that lies beyond space and time was assumed to be the modus operandi for every religion in the face of Covid-19. Thus, a new psychology of religion in the post Covid-19 era would take into consideration the meaning of these symbols - the locked church and the bonding family relationships, encouraging openness to love and acceptance of everyone as a fellow vulnerable being in the world. But what does that mean to the African peoples?

The present state of religious-related abnormalities in Nigeria, for instance, call to mind a statement by one of the earliest colonial officials in West Africa: In 1858, Thomas Hutchinson, the then British Consul for West Africa, had described the intelligence (and we could add, consciousness, understanding, and even mentality) of the Black people as being "in a condition little better than that of helpless infancy" (Hutchinson 2017, p. vi). "Helpless infancy" says a lot about the discomfort of the African reader. But then, the incessant fights to exterminate a fellow Black brother or sister in the name of imported religions seem to vindicate Hutchinson even today. Describing the Black person in those vitriolic words could qualify as reaction formation (a defense mechanism) on the part of the consul. On our part, remaining at the level we are as Africa's religious brutes, biting, and killing each other in the name of God (Allah) could be a form of learned helplessness (a concept we can unveil from Hutchinson's bitter words). Chung Choi, and Du (2017) have highlighted the cognitive element in Martin Seligman's original experimental theory of learned helplessness. The theory is rooted in the inability to escape harmful situations due to past failures at attempts. If the Whiteman came to help, yet, left Africa more divided, then, that constitutes a form of failure, a woeful one at that due to the superior status accorded the foreigner by the Blackman (Mayer 2002). Such a failure has become a part of the "fertile ground" which inverts even the best tools of freedom as weaponry, as we have it in our altercative religious practices. Yet, again, the pandemic sent us all back home to put our houses in order as it were. So, for Africans, the symbolic gesture of going back home means redefining themselves first as "Black and Brethren" before "foreign goods" including religion can make more sense. The "call of the pandemic" is to see the goodness of the home(land) which colonialism did not see, with all that came with it.

\section{Conclusion}

Some contemporary scholars in psychology have applied different theories to the societal life. This paper followed a similar pattern, bringing Piaget's learning and developmental theories to bear on the life of postcolonial societies. The pandemic opened wide a window to critiquing some religious practices and especially the biting tone that has come to define 
inter-religious cultures. Some multi-religious societies in Africa have suffered for lack of understanding among their various religious bodies. For instance, Nigeria has witnessed even shortly before the Covid-19 some disruptive relationships between Christians and Muslims culminating in the murder of a seminarian. As the pandemic opens a new chapter of life, it then becomes anachronistic to keep fighting for religious reasons in a world that witnessed the closure of doors in houses of worship for every religion.

The pandemic, in a way, has condemned the robotic practice of religion. This kind of practice, which might bear the mark of low consciousness, means "killing because I was told that killing is good" (by my religious leader or my sacred text). In such a mindset, there is no reasoning together, and the sense of agency diminishes. For the Black people of Africa who take delight in ideas that foreign cultures (White or Brown) transplanted haphazardly to their land during and beyond colonialism, this might be the right time to take off the mask and wake up to the enduring call of great thinkers like Fanon (1967) and Spivak (1988). Both have voiced out on what is still to be done by the natives to complement the life they have been subjected to, including the belief in the "external supernatural" of the Whiteman. Like Reinhartz (2001), postcolonial societies should be concerned about the ethnic origins of so-called world religions and the ideologies that guided their emigration to other places. Stretching Reinhartz's idea further would imply that each culture rethinks its inherent primary quality before adapting to the mega religious (secondary) forces operating in its vicinity. For instance, Christians and Muslims in various villages of Nigeria can look at their skin color and the geographic locations of their respective "mother" religious headquarters and gain some insight as to why they should no longer be fighting and killing each other in the name of religion. This can help make room for an optimal development of agency in places like Africa where overt empty religiosity overshadows so-called democracy and the rights of citizens as human beings. The Piagetian accommodationassimilation dyadic model of learning, and of life, is a possible terrain within the window that the pandemic has opened for postcolonial societies. Utilizing these psychological tools means going beyond defining oneself as being a mere Christian or Muslim, confining oneself to space and time as it were (in a pre-pandemic model), and refusing to resume a life of being human again. Christianity and Islam came to Africa to be assimilated (to aid societal growth) not accommodated (to change the people). This pattern was inverted due to some of the factors we have highlighted in previous sections. It is time to employ these learning theories to upturn that error of inversion for the good of all.

Amidst the negative impact due to Covid-19, there seems to be something positive especially for postcolonial societies. Everyone went back home to take care of family, the base of life, our loved ones, and everyone became more aware of his/her role towards the individual, the social, and the societal. What more religious principle is better than thatloving as oneself? Yet, Reinhardt (2001) shows how one religion can predicate its values on the already established foundation, introducing a certain form of dilemma and baiting loyalty, as we have in Christianity building and developing upon Judaism. The same lens is projected on Christianity and Islam building on African Traditional Religions with the latter representing a weightier form of African agency. Agency means acknowledging that our forefathers and mothers lived a wholesome life before colonialism, and with their traditional tools including religion. They survived; we can survive too if we pay attention to what is ours that colonialism swept underneath our feet. It also means telling ourselves the truth and accepting the fact that, like every other society, the African was/is not perfect; hence, the need to pull from each aspect of the foreign life that came during colonialism only the good and unifying ideas. Covid-19 can be a time to shift and to rebuild our world, prioritizing our agency over foreign baits. 
With Hayes et al (2015), we subscribe to the idea that "flexibly modifying threatened beliefs... selectively accommodating certain beliefs against threat" (p. 522) is a good stance during crisis. Standing on what one knows and refusing to shift is the basis of cultural truism-a belief system that appears to survive until a rational argument makes it crumble. This false life - that we (Africans) are doing right because we are living on two mainstream foreign religions that make us kill one another-should be toppled peacefully through utilizing the Piagetian tools of accommodation and assimilation. This call means reflecting and acting upon the role of the agent, as in affirming ourselves ("we the Black people") first before looking at what the Whiteman (Christian) or Brownman (Muslim) brought, including religion. A call to right the wrong always evokes some anxiety, and the ideas we have shared about religion in Nigeria can fit into that pattern. But the chief informant of this article, Piaget (together with George Kelly) is seen as one who showed the role of accommodation (and assimilation) in anxiety management and belief system. For the duo, the idea that "accommodating beliefs may quell the anxiety that is aroused by threats to those beliefs" is "the engine room for significant changes in beliefs" (Hayes et al. 2015). Postcolonial societies are called to reflect on the meanings of these great ideas from psychology for the good of our land: "Assimilate if you can; accommodate if you must" (Block 1982; Hayes et al. 2015) is a good advice. But the question remains: which home did you go back to at the onset of Covid-19?

\section{References}

Achebe, C. (2017). Things fall apart. New York: Penguin Books.

Akpan, J. (2020). Black Racial Trauma at the Intersection of Postcoloniality and Psychoanalysis. Abstract. 2020 Conference. Association for the Psychoanalysis of Culture and Society. https://www.conftool.net/ apcs2020/index.php?page=browseSessions\&form_session=99\&presentations.

Beins, B. (2016). Early tests of Piagetian theory through World War II. The Journal of Genetic Psychology, 177(6), 252-264. https://doi.org/10.1080/00221325.2016.1237236

Bennett, J., Froggett, L., \& Muller, L. (2019). Psychosocial aesthetics and the art of lived experience. Journal of Psychosocial Studies, 12(1-2), 185-201. https://doi.org/10.1332/147867319x15608718111023

Blackmore, S., \& Troscianko, E. (2018). Consciousness: An introduction. Abingdon: Routledge.

Block, J. (1982). Assimilation, accommodation, and the dynamics of personality development. Society for Research in Child Development, 53, 281-295.

Brown, B. (2017). Braving the wilderness: The quest for true belonging and the courage to stand alone. New York: Random House.

Chappell, C., Tomcho, T., \& Foels, R. (2020). Psychology of religion courses in the undergraduate curriculum. Psychology of Religion and Spirituality, 12(2), 241-246. https://doi.org/10.1037/rel0000188

Chung, G., Choi, J., \& Du, J. (2017). Tired of Innovations? Learned helplessness and fatigue in the context of continuous streams of innovation implementation. Journal of Organizational Behavior, 38, $1130-1148$.

DeRobertis, E. (2020, April 16). Piaget and Husserl: Comparisons, contrasts, and challenges for future research. The Humanistic Psychologist, Advance Online Publication, https://doi.org/10.1037/hum0000183.

Dueck, A. \& Marossy, M. (2019). A future for the indigenous psychology of spirituality. Theoretical and Philosophical Psychology, 39(2), 120-126. https://doi.org/10.1037/teo0000116.

Esteves, J. (2020). Seminarian murdered by kidnappers in Nigeria. America: The Jesuit Review. https:// www.americamagazine.org/politics-society/2020/02/03/seminarian-murdered-kidnappers-nigeria.

Fanon, F. (1967). Black skin, white mask. Trans. Richard Philcox. New York: Grove Press.

Gershon, I. (2011). Neoliberal agency. Current Anthropology, 52(4), 537-555.

Grzyb, A. (2019). Unsettled memory: Genocide memorial sites in Rwanda. The Brown Journal of World Affairs, 25(2), 185-198.

Hayes, J., Schimel, J., Williams, T., Howard, A., Webber, D., \& Faucher, E. (2015). Worldview accommodation: Selectively modifying committed beliefs provides defense against worldview threat. Self and Identity, 14(5), 521-548. https://doi.org/10.1080/15298868.2015.1036919 
Hook, D. (2012). A critical psychology of the postcolonial: The mind of apartheid. New York: Psychology Press.

Hutchinson, T. (2017). Impressions of Western Africa. London: Longman.

Kellond, J. (2019). Present-day troubles: Winnicott, counter-culture and critical theory today. Psychoanalysis, Culture \& Society, 24(3), 323-343.

Kunkel, M. (2017). Introduction to general psychology. Carrolton, GA: University of West Georgia Press. http://bit.ly/2tY3tnn.

Kunkel, M. (2018). Allegories for psychotherapy, teaching, and supervision. Cham, Switzerland: Palgrave McMillan.

Lancaster, B. (2004). Approaches to consciousness: The marriage of science and mysticism. New York, NY: Palgrave Macmillan.

Langsdorf, L. (1980). Schutz's theory of relevance. Human Studies, 3, 403-410.

Mayer, S. (2002). Psychology in Nigeria: A view from the outside. Ife PsychologIA - An International Journal 18(1), 1-8. http://researchgate.net/publication/272341463.

Reinhartz, A. (2001). Befriending the beloved disciple: A Jewish reading of the gospel of John. New York: Bloomsbury.

Roth, W. (2018). Translation and its consequences in qualitative social research: On distinguishing "the social" from "the societal." Forum: Qualitative Social Research 19(1), Art. 12.

Rutherford, G. (2011). A Model of assimilation and accommodation in the cognitive \& cultural realms. Dynamical Psychology. http://dynapsyc.org.

Sampson, I. (2014). Religion and the Nigerian state: Situating the de facto and de jure frontiers of statereligion relations and its implications for national security. Oxford Journal of Law and Religion, 3(2), 311-339. https://doi.org/10.1093/ojlr/rwt026

Spivak, G. (1988). Can the subaltern speak? In C. Nelson \& L. Grossberg (Eds.), Marxism and the Interpretation of Culture (pp. 271-313). Urbana and Chicago: University of Illinois Press.

Tan, Y. (2006). The Johannine community: Caught in two worlds. In F. Lozada \& T. Thatcher (Eds.), New currents through John: A global perspective (pp. 167-179). Atlanta: Society of Biblical Literature.

Valsiner, J. (2005). Participating in Piaget. Society, 42, 57-61. https://doi.org/10.1007/BF02687400

Weiner, T. (2011). The (un)managed self: Paradoxical forms of agency in self-management of bipolar disorder. Culture, Medicine, and Psychiatry, 35, 448-483.

Publisher's Note Springer Nature remains neutral with regard to jurisdictional claims in published maps and institutional affiliations. 